\title{
Erratum to: The effect of postoperative wound infections on functional outcome following intra-articular calcaneal fractures
}

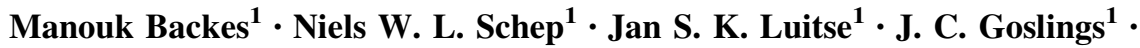 \\ Tim Schepers ${ }^{1}$
}

Published online: 24 June 2015

(C) Springer-Verlag Berlin Heidelberg 2015

\section{Erratum to: Arch Orthop Trauma Surg \\ DOI 10.1007/s00402-015-2219-5}

The original version of this article unfortunately contained a mistake and has been corrected. The fourth author J. Carel Goslings's family name has been published incorrectly. The correct family name should be Goslings.

The online version of the original article can be found under doi:10.1007/s00402-015-2219-5.

Manouk Backes

m.backes@amc.nl

1 Trauma Unit, Department of Surgery, Academic Medical

Center, Meibergdreef 9, PO Box 22660,

1100 DD Amsterdam, The Netherlands 